\title{
The optimization of treatment planning and ablation rate improvements on feasibility of pediatric MR-HIFU applications
}

\author{
Doug Wackerle ${ }^{1 *}$, Haydar Celik², David Kinnaird², Daniel Yang ${ }^{3}$, Avinash Eranki $^{2}$, Matthew Oetgen², AeRang Kim², \\ Karun Sharma ${ }^{2}$, Harry Kim ${ }^{4}$ Peter Kim², Pavel Yarmolenko ${ }^{2}$
}

From Current and Future Applications of Focused Ultrasound 2014. 4th International Symposium

Washington, D.C, USA. 12-16 October 2014

\section{Background/introduction}

Magnetic resonance-guided high intensity focused ultrasound (MR-HIFU) ablation provides a precise, non-invasive treatment for lesions in adults. In children, MRHIFU's potential remains largely unexplored, though its non-invasive and non-ionizing nature holds promise. Yet, pediatric patients pose challenges affecting treatment: young children require general anesthesia, exhibit wide ranges of anatomy, and have varying lesion sizes and locations. These demonstrate a need for standardized treatment approaches and physical aids to optimize patient position, reduce time-intensive repositioning, and thus reduce overall treatment time. Further improvement of ablation rate and reduction of risk are also possible via improved monitoring of skin temperature during ablation and mild hyperthermia. Improvements in treatment planning and volumetric rate may save time and allow for treatment of larger lesions, increase patient throughput, and possibly increase efficacy and lower cost. This study aims to quantify and examine how such improvements could increase the time allocated for direct ablation and produce better outcomes.

\section{Methods}

Forty-one pediatric patients with various limb tumors at Children's National Medical Center from November 2005 to October 2013 were examined retrospectively as potential candidates for MR-HIFU ablation therapy. After identifying the tumor location, software (Avizo Standard Edition 8.0.0, Visualization Sciences Group, SAS, Berlin, Germany) was used to define its area through axial slices

${ }^{1}$ The George Washington University School of Medicine, Washington, D.C., United States

Full list of author information is available at the end of the article and create a 3D segmented model to measure its volume. As a reference, treatment time was estimated at a maximum $(180 \mathrm{cc} /$ hour $)$ rate used in ablation of uterine fibroids (obtained from Phillips Healthcare, Vantaa, Finland).

Four hours maximum anesthesia time was selected due to risks to children and restraints on surgeon time and focus, room and machine time, and cost. Tumor volume and ablation rate data was graphically combined to show effects of theoretical improvements.

\section{Results and conclusions}

Increasing the time available for ablation can substantially increase treatable tumor volume. In the examined 41 patients, utilizing only 1 hour for ablation (at $180 \mathrm{cc} /$ hour) leaves 13 patients (32\%) untreated. With more time, all but 2 patients $(5 \%)$ are treatable with 3 or 4 hours of ablation. Conversely, complete treatment of a lesion is directly related to ablation rate. At the current rate of $(180 \mathrm{cc} /$ hour), 2 (5\%) are untreatable, yet with double the current rate (360 cc/hour), all 41 lesions can be treated. Improvements in planning guidelines and treatment rates could have substantial impacts on the effectiveness of MR-HIFU ablation and the size of treatable tumors and number of patients treated with this technique.

\section{Acknowledgements (Funding) \\ This study was conducted at The Sheikh Zayed Institute at Children's National Medical Center and funded by the W.T. Gill, Jr. Summer Research Fellowship through The George Washington University School of Medicine.}

\section{Authors' details}

${ }^{1}$ The George Washington University School of Medicine, Washington, D.C., United States. ${ }^{2}$ Children's National Health System, Washington, D.C., United States. ${ }^{3}$ Princeton University, Princeton, New Jersey, United States. ${ }^{4}$ Texas Scottish Rite Hospital for Children, Dallas, Texas, United States. 


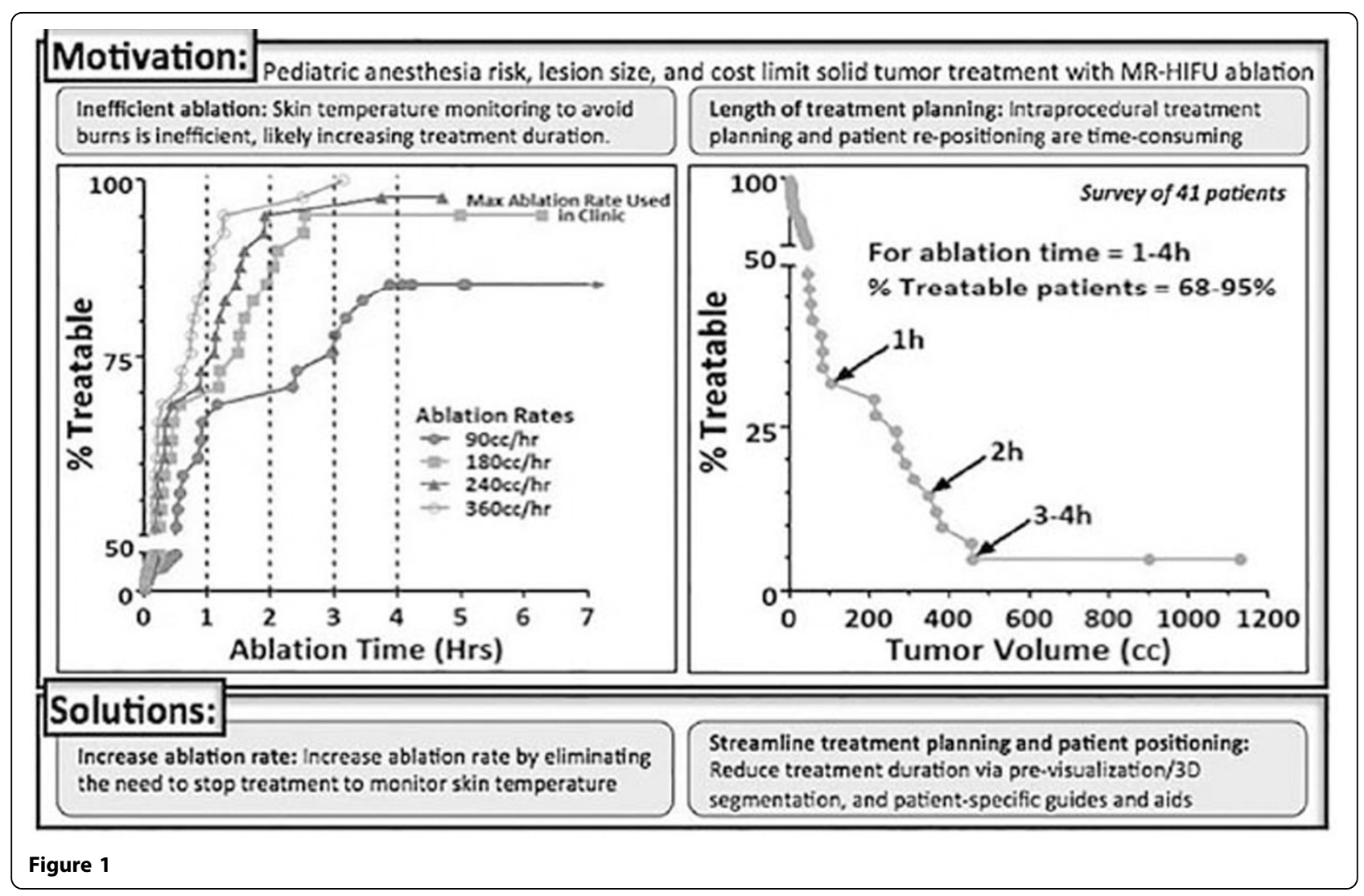

Published: 30 June 2015

doi:10.1186/2050-5736-3-S1-P77

Cite this article as: Wackerle et al: The optimization of treatment

planning and ablation rate improvements on feasibility of pediatric MR-

HIFU applications. Journal of Therapeutic Ultrasound 2015 3(Suppl 1):P77.
Submit your next manuscript to BioMed Central and take full advantage of:

- Convenient online submission

- Thorough peer review

- No space constraints or color figure charges

- Immediate publication on acceptance

- Inclusion in PubMed, CAS, Scopus and Google Scholar

- Research which is freely available for redistribution 